\title{
One-year assessment of physical activity level in adult Qatari females: a pedometer-based longitudinal study
}

This article was published in the following Dove Press journal:

International Journal of Women's Health

19 July 2016

Number of times this article has been viewed

\section{Suzan Sayegh \\ Mercia Van Der Walt \\ Mohamed Ghaith Al-Kuwari}

Exercise is Medicine Department, Aspetar Orthopedic and Sports Medicine Hospital, Doha, Qatar
Correspondence: Suzan Sayegh Exercise is Medicine Department, Aspetar Orthopedic and Sports Medicine Hospital, PO Box 29222, Doha, Qatar Email souzan.alsayegh@aspetar.com
Background: Physical inactivity is a growing health concern and has been identified as the fourth leading risk factor for global mortality. The Arab region includes countries with some of the world's highest physical inactivity levels, such as Qatar, more specifically the Qatari female population.

Objective: The objective of this study is to assess the physical activity levels of Qatari national female adults during a 1-year pedometer-based program.

Materials and methods: A total of 549 Qatari national females aged between 18 years and 64 years were included. Data extracted from "Step into Health" program web database in Qatar were used for analyses. Daily habitual physical activity (daily total step count and aerobic steps) was assessed through the Omron HJ-324U pedometer. Step counts were classified as follows: $<5,000$ steps/d, sedentary; 5,000-7,499 steps/d, low active; and $\geq 7,500$ steps/d, physically active. Statistical significance was set at $P$-value $\leq 0.05$. Descriptive statistics were used, and habitual physical activity was calculated through repeated measures analysis of variance to determine the difference across the monitored days.

Results: Mean age was $37.4 \pm 11.7$ years, and median body mass index of $28.8 \mathrm{~kg} / \mathrm{m}^{2}$ (interquartile range $24.8-33.5$ ). Daily steps for the overall population ranged from 3,505 steps/d to $10,010 \mathrm{steps} / \mathrm{d}$, with a median of $6,008 \mathrm{steps} / \mathrm{d}$. A total of $242(44.1 \%)$ females were sedentary, 178 (32.4\%) were low active, and 129 (23.5\%) were physically active. The physically active group showed a median of 927 aerobic steps/d (interquartile range 0-4,248).

Conclusion: Based on the results of this study, Qatari females are not meeting the global recommendations of physical activity. Future research might need to consider barriers to physical activity as well as social, cultural, and environmental factors.

Keywords: aerobic steps, daily steps, step count, community-based program

\section{Introduction}

Physical inactivity is a growing health concern worldwide. Recently, it has been identified as the fourth leading risk factor for global mortality, contributing to $6 \%$ of deaths around the world. ${ }^{1}$ Physical inactivity is associated with noncommunicable chronic diseases such as obesity, hypertension, and diabetes. ${ }^{2}$ This is mainly caused by the global lifestyle changes, specifically the spread of Western lifestyle, which is characterized by reduced physical activity and unhealthy diet. ${ }^{3,4}$ The prevalence of insufficient physical activity is high in the World Health Organization (WHO) region of the US (32\%) and the Eastern Mediterranean Region (31\%). ${ }^{5}$ Moreover, the Arab region includes countries with some of the world's highest physical inactivity levels. ${ }^{6}$ Statistics show that physical inactivity is highly prevalent in Qatar and the countries 
of the Gulf Cooperation Council. For instance, Saudi Arabia has the highest prevalence rate of physical inactivity in the Gulf area (69\%), followed by Kuwait (64\%), United Arab Emirates (62\%), and Qatar (46\%). ${ }^{5,7}$ Such high rates are mainly caused by the remarkable change in physical activity patterns in the Arab world, especially within the Gulf region, for reasons related to the desert climate in the region and the adoption of Western habits. As such, there is a higher reliance on modern ways of transportation and increased sitting time commonly through watching television, using the internet, and playing electronic games. ${ }^{5}$ Although physical activity is a main determinant factor of health, the Qatari population, especially females, remain inactive. Based on the Qatar Stepwise Report 2012, 45.9\% of the studied population have a low physical activity prevalence rate, whereas $31.3 \%$ are found to be highly active and $22.8 \%$ are moderately active. Females are also considered as less active than males with a "low physical activity" prevalence rate of $54.2 \%$ compared with $37.4 \%$ among males. However, the overall "high physical activity" prevalence rates were $38.1 \%$ and $24.8 \%$ among males and females, respectively, versus approximately comparable "moderate physical activity" rates of $24.6 \%$ and $21.0 \%$ among males and females, respectively. ${ }^{7}$

Based on the WHO global recommendations for physical activity, adults aged 18-64 years should be physically active for a minimum of $150 \mathrm{~min} / \mathrm{wk}$, which is equal to 30 minutes five times a week. ${ }^{8}$ Consequently, some studies identified a duration of 30 minutes of moderate-intensity walking as equivalent to $3,000-4,000$ steps/d. ${ }^{9,10}$ On the other hand, according to the WHO, aerobic activity could be done in periods of 10 minutes duration at least. ${ }^{8}$ These recommendations are found to improve health and wellbeing taking into consideration the components of physical activity, which encompass the mode, intensity, duration, and frequency. ${ }^{11,12}$ The State of Qatar has recently launched the National Physical Activity Guidelines (NPAG-Q), 2014, as a reliable resource for educators, physicians, practitioners, and individuals who seek to prescribe physical activity or even engage in physical activity. This NPAG-Q not only provides guidance but also encourages and assists people to adopt healthier lifestyles. For instance, adults of age between 18 years and 64 years are advised to participate in $5 \mathrm{~d} / \mathrm{wk}$ of 30 minutes moderate intensity physical activities or at least $3 \mathrm{~d} /$ wk of vigorous intensity exercises. ${ }^{13}$ Despite the fact that some studies in Qatar address obesity and overweight, few of these studies address the female population, specifically, and their physical activity status. The objective of this study is to assess the physical activity levels of Qatari national female adults (aged 18-64 years) during a 1-year pedometer-based program.

\section{Materials and methods Description of the "Step into Health" program}

Step into Health (SIH) is a community-based program that was launched in 2012 by Aspire Zone Foundation (AZF), Qatar, as an approach to improve physical activity across the population of Qatar. This program was initially designed for males, females, and teenagers older than 16 years. SIH program was publicized through an initial campaign followed by subsequent advertisement campaigns. Later, more people were added to the program after the initiation of outreach campaigns within the workplaces and university campuses in Qatar. They were informed about the importance of reaching the target of 10,000 steps/d. Registration in this program was noncompulsory and based on individuals' personal choice. The program mainly involves the distribution of pedometers to registered members to track their step counts. These pedometers have a feature that enables individuals to upload their recorded information electronically through a USB connection and are supported by a self-monitoring online account that is linked to a web database managed by AZF. Registered members were encouraged to frequently upload their pedometer readings onto their account on the program website (http://www.stepintohealth.qa/) by providing them with instructions about the device utilization and data upload. Automated emails and text messages were sent to members as reminders to upload their data at intervals of 14 days, 21 days, and 28 days from the last date uploaded within the first 6 months of this study period. Members were recommended to wear the pedometer at their waist the whole day and take it off during sleep time and water-based activities. SIH is a nationwide community-based program, which was advertised via television, newspapers, billboards, malls, and social media. The catch to join the program was a free pedometer (which is linked to an online registration) and a basic medical checkup. Within 3 weeks, a target of 10,000 people was reached. Then, after the initial month the medical checks stopped; however, the distribution of free pedometers was continued.

\section{Study design and population}

This is part of a longitudinal study whereby cross-sectional analyses were conducted to assess the current status of adult Qatari females' physical activity level based on their step counts over a period of 1 year. Data were gathered from the SIH web database for the specified period. A total of 549 Qatari national females aged between 18 years and 
64 years were selected representing various communities within the SIH program, which include individuals from the public, universities, and companies. The study included only females who uploaded their data for at least 6 months out of 12 months and a minimum of 7 consecutive $d / w k$ within the study period. Females achieving 1,000 daily steps and below or more than 65,000 steps/d were excluded from this study to ensure valid activity data. Baseline data from pedometer step counts were used and then analyzed at the 6th month and 12 th month of the study period.

\section{Study measures}

Age, height, and weight were self-reported; accordingly, the body mass index (BMI) was calculated based on the formula: weight $(\mathrm{kg})$ divided by height squared $\left(\mathrm{m}^{2}\right)$. Based on the WHO classification, normal weight was defined as BMI $\leq 24.9$, overweight as BMI 25-29.9, and obese as BMI $\geq 30 .{ }^{14}$ Daily habitual physical activity was assessed through the Omron HJ-324U pedometer (Omron Healthcare Co., Ltd., Kyoto, Japan), which was used to record the total step count and aerobic steps each day.

\section{Physical activity assessment}

In order to assess the individuals' physical activity level, they were categorized according to their recorded daily steps. Steps were classified as follows: those who achieve $<5,000$ steps/d are "sedentary", others achieving between 5,000 steps/d and 7,499 steps/d, inclusive, are considered as "low active", and those who complete $\geq 7,500$ steps/d are classified as "physically active". ${ }^{15,16}$ Aerobic step counts are computed separately by the pedometer when a person walks $>60 \mathrm{steps} / \mathrm{min}$ for a duration of 10 minutes successively, as per the manufacturer's definition. ${ }^{17}$ However, some studies refer to intensity-based steps per day, where it is suggested that a reliable estimate of moderate intensity physical activity is $100 \mathrm{steps} / \mathrm{min} .{ }^{18-23}$ Our classification was based on the $100 \mathrm{steps} / \mathrm{min}$ for moderate intensity physical activity although the "manufacturer"defined aerobic steps were used as a basis of calculation focusing on using the total steps and duration. Therefore, in our analyses we translated the duration of 30 minutes of moderate intensity physical activity five times a week, as per the WHO physical activity recommendations and the NPAG-Q, into a total of 3,000 aerobic steps/d, which is also equivalent to 2,100 aerobic steps/d for 7 days a week.

\section{Statistical analyses}

Data were analyzed using the IBM Statistical Package for Social Sciences (SPSS Version 21.0; IBM Corporation, Armonk, NY, USA). Descriptive statistics (mean $\pm \mathrm{SD}$ ) for the normally distributed data are used to summarize the general characteristics of the study population. Skewed continuous data are presented as median (interquartile range, IQR) and categorical data are given as counts (percentages). Study subjects were classified into three categories based on their average daily steps per day (sedentary: $<5,000$ steps/d, low: 5,000-7,499 steps/d, and active: $\geq 7,500$ steps/d). Associations between categorical variables were tested using the chi-square $\left(\chi^{2}\right)$ test and a one-way analysis of variance (ANOVA) was used to analyze the difference between the categories. The statistical significance was set at a $P$-value of $\leq 0.05$. Habitual physical activity was assessed using repeated measures ANOVA to determine the difference across the monitored days.

\section{Ethical considerations}

The study was approved by the Clinical Research Ethics Committee of Aspetar/Al-Shaffalah (Project No 2013-004). The members are requested to agree on the "terms of use" upon registration on the website, which include details regarding their privacy, personal data protection, and consent for use of data in research. Confidentiality and anonymity were assured for all data handled.

\section{Results}

As mentioned earlier, the study included 549 adult Qatari national females. The results show that the population under study have a mean age of $37.4 \pm 11.7$ years, weight $75.4 \pm 20.0 \mathrm{~kg}$, and a median BMI of $28.8 \mathrm{~kg} / \mathrm{m}^{2}$ (IQR 24.8-33.5) as displayed in Table 1.

Moreover, the classification of the study population based on their physical activity level, as per Tudor-Locke et al, ${ }^{16}$ is presented in Table 1. The results show that majority of the study population, 242 females (44.1\%), were categorized in the sedentary group as they have achieved $<5,000 \mathrm{steps} / \mathrm{d}$. On the other hand, 178 females (32.4\%) out of the total population were classified as low active (achieving 5,000-7,499 steps/d), followed by a total of 129 females $(23.5 \%)$ in the physically active category (achieving $\geq 7,500$ steps/d). There was a significant difference in age $(P<0.001)$ between the categories where the mean age was $35.5 \pm 11.3$ years in the sedentary group, compared to $37.1 \pm 11.8$ years and $41.2 \pm 11.1$ years within the low active and physically active groups, respectively, as shown in Table 1. However, the physically active category showed a higher significant age difference compared with sedentary $(P=0.001)$ and low active $(P<0.007)$ categories. Furthermore, the results show that more than half of the study population $(53.6 \%)$ are between the age of 25 years and 44 years compared to 
Table I Classification of the study population based on their physical activity level

\begin{tabular}{|c|c|c|c|c|c|}
\hline Characteristic & $\begin{array}{l}\text { Overall } \\
\text { population }\end{array}$ & $\begin{array}{l}\text { Sedentary } \\
<5,000 \text { steps } / \mathrm{d}\end{array}$ & $\begin{array}{l}\text { Low active } \\
5,000-7,499 \text { steps/d }\end{array}$ & $\begin{array}{l}\text { Physically active } \\
\geq 7,500 \text { steps } / \mathrm{d}\end{array}$ & $P$-value \\
\hline Total & $549(100)$ & $242(44.1)$ & $178(32.4)$ & $129(23.5)$ & \\
\hline Age (years) & $37.4 \pm 1 \mathrm{I} .7$ & $35.5 \pm 11.3$ & $37.1 \pm 11.8$ & $41.2 \pm I I .1$ & $<0.001$ \\
\hline \multicolumn{6}{|l|}{ Age groups (years) } \\
\hline $18-24$ & $94(17.1)$ & $45(47.8)$ & $34(36.2)$ & $15(16.0)$ & $<0.001$ \\
\hline $25-44$ & $294(53.6)$ & $143(48.7)$ & $90(30.6)$ & $61(20.7)$ & \\
\hline $45-64$ & $161(29.3)$ & $54(33.5)$ & $54(33.5)$ & $53(33.0)$ & \\
\hline Weight (kg) & $75.4 \pm 20.0$ & $75.1 \pm 19.2$ & $76.3 \pm 23.2$ & $74.7 \pm 16.5$ & 0.747 \\
\hline BMI $\left(\mathrm{kg} / \mathrm{m}^{2}\right)$ & $28.8(24.8-33.5)$ & $28.7(24.1-33.6)$ & $28.5(25.1-33.9)$ & $28.8(24.9-32.4)$ & 0.775 \\
\hline Daily step count & $6,008(3,505-10,010)$ & $3,342(2,222-4,935)$ & $5,656(3,8 \mid 4-7,977)$ & $10,150(7,100-13,009)$ & $<0.001$ \\
\hline Aerobic steps & $0(0-1,500)$ & $0(0-0)$ & $0(0-0)$ & $927(0-4,248)$ & $<0.001$ \\
\hline
\end{tabular}

Notes: Values are expressed as count (\%), mean $\pm S D$, or median (interquartile range). Values in bold are statistically significant at $P \leq 0.05$.

Abbreviations: BMI, body mass index; SD, standard deviation.

$29.3 \%$ of them falling in between 45 years and 64 years, and $17.1 \%$ who are between 18 years and 24 years. It is also noticed that those $<45$ years old are classified as sedentary, ie, $<5,000$ steps/d. As per the BMI results, there was no statistically significant difference recorded between the three groups $(P>0.001)$. Moreover, Figure 1 shows the median steps per day among the different age groups of the study population. The figure shows that middle-aged adult females (45-64 years) are more active, with a daily average of $>7,000$ steps, compared to $\sim 5,000$ steps $/ \mathrm{d}$ and 5,400 steps/d among age groups 18-24 years and 25-44 years, respectively.

Physical activity measurements (Table 1) show that daily steps for the overall population ranged from 3,505 steps/d to $10,010 \mathrm{steps} / \mathrm{d}$, with a median of $6,008 \mathrm{steps} / \mathrm{d}$, distributed within the three groups as follows: 3,342 steps/d (IQR 2,222-4,935) in the sedentary, compared to 5,655 steps/d (IQR 3,814-7,977) in the low active, and 10,150 steps/d (IQR 7,100-13,009) in the physically active group. On the other hand, the only result recorded for aerobic steps was

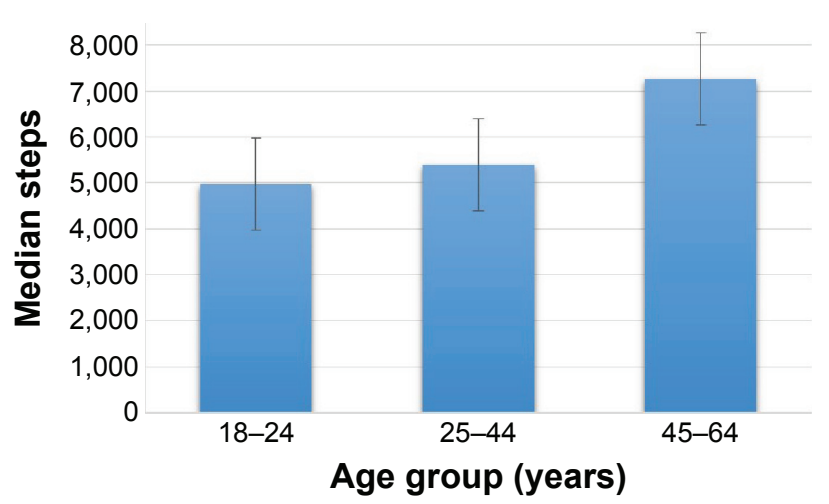

Figure I Median steps/day among the different age groups of the study population. in the physically active group with a median of 927 steps/d (IQR 0-4,248).

Furthermore, the daily physical activity level of study subjects is illustrated in Figure 2. As shown in the graph, step counts start to rise slowly at the beginning of the week (Sunday) and peak by midweek (Tuesday) with a median of $\sim 6,200$ steps/d (IQR 3,589-10,073). A gradual decline in step counts is then noticed, reaching a median of $\sim 5,600$ steps/d (IQR 3,270-9,670) on Friday and then starts to rise again by Saturday. As per the step count variations over the study period of 12 months, the results are displayed in Figure 3. The graph shows an increase in the median step counts at baseline where it reaches $\sim 6,000$ steps/d (IQR 3,441 to 10,082). However, a gradual decrease in the median steps is observed reaching 5,584 steps/d (IQR 3,226-9,586) at month 6. Then, a gradual increase was noticed by the end of the year, at the 12th month. The overall trend line shows an increase in the median step counts of the study population throughout the study period.

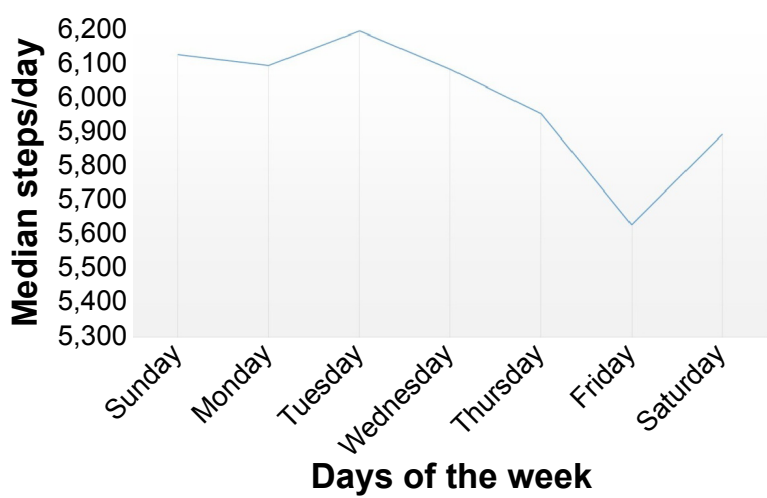

Figure 2 Step-count median variations per weekdays. 


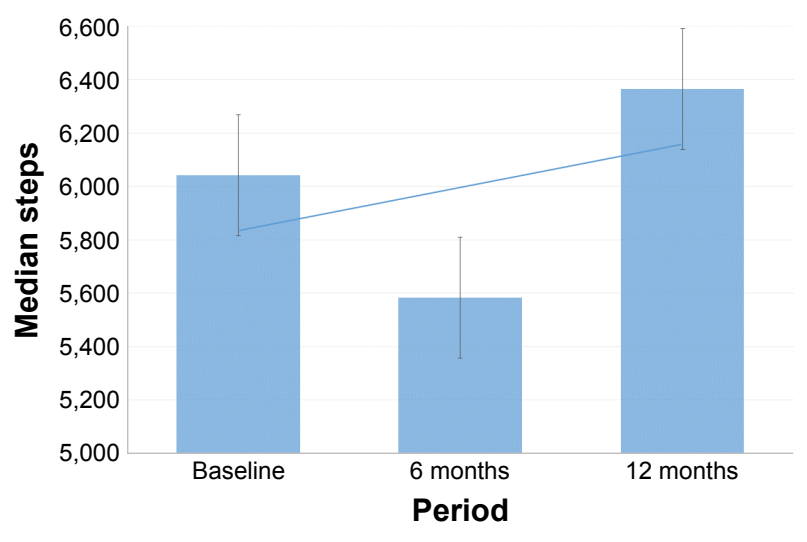

Figure 3 Pedometer measures at baseline, 6 months, and 12 months.

\section{Discussion}

On average, the study population were roughly middle aged (mean age $=37.4$ years) and are classified as overweight (mean BMI $=29.6 \mathrm{~kg} / \mathrm{m}^{2}$ ); however, they were on the edge of being obese. Although it is well established in the literature that physical inactivity highly contributes to overweight and obesity, ${ }^{24}$ our findings did not show a significant difference in BMI across the three physical activity categories, which might be due to the high obesity and overweight rates in Qatar. ${ }^{25}$ It was found that younger females were less active than the older as they make up more than half of the population under study. In fact, these results, specifically average age, show that females are more active as they get older (Table 1).

As the literature suggests, females in Qatar are less active due to certain cultural restrictions and other social factors. Exercise is not widely accepted among Arab women, which is one of the main causes of increased obesity. ${ }^{26}$ Barriers to physical activity are found to greatly influence their decision to engage in routine physical activity, which is mainly affected by their cultural beliefs, values, and practices. ${ }^{27}$ However, health-related factors might facilitate physical activity among older females, such as deteriorating health, which can reduce the ability to exercise, but at the same time can stimulate physical activity as a protective act. Other factors might include having more leisure time, receiving physician recommendations, or accessibility to a fitness facility. ${ }^{28}$

Moreover, the literature is consistent with our observed findings; the median daily step count, 6,008 steps/d, shows that the study population fell in the "low active" group (Table 1). The results indicate that majority of the study population do not meet the WHO global recommendations for physical activity and the NPAG-Q. Even though 23.5\% females were physically active, still, they do not meet the aforementioned physical activity recommendations due to the low aerobic steps as the median aerobic steps are equal to $927 \mathrm{steps} / \mathrm{d}$ (IQR 0-4,248). In order to meet the physical activity recommendations, a person must achieve either 3,000 aerobic steps/d for 5 days a week or 2,100 aerobic steps/d for 7 days a week, which is equal to $150 \mathrm{~min} / \mathrm{wk}$ of moderate-to-vigorous activity, as mentioned under the "Materials and methods" section.

Additional findings show that physical activity level among the study population varies throughout the week (Figure 2); they tend to be more active during weekdays rather than weekends. Previous studies have also revealed that physical activity was higher on weekdays compared with weekends. ${ }^{29-31}$ The physical activity level was higher at the beginning of the week, ie, on Monday and Tuesday, and decreased toward the end of the week. This weekly rhythm has a strong impact on individuals' quality of life, which is more environmental related and behavioral related rather than biological. ${ }^{32}$ The days of the week are more likely to regulate the sleeping patterns, eating habits, and physical activity. ${ }^{29,33-35}$

Moreover, Qatar has a dry, subtropical desert climate, which is characterized with low annual rainfall and intensely hot and humid summers. Spring and autumn, on the contrary, are warm and the evenings are pleasantly cool. The results in Figure 3 present the step count median variations over a 12 -year period. The graph shows an alteration in the physical activity level throughout the year. There is an observed decrease in the median steps per day among the study participants, especially during extremely hot temperature as in June, July, and August. This significant drop in the level of physical activity during this period of the year can also be due to the occurrence of "Holy Month of Ramadan". Several studies state that poor weather is perceived as a barrier to physical activity, where weather conditions can either highly promote or prevent physical activity behaviors. ${ }^{36-38}$ At certain areas, weather restrictions, such as humidity and temperature, may have some effects on the month-by-month physical activity levels. This is the case in Qatar, since the summer season has an extreme heat condition with the temperature reaching $50^{\circ} \mathrm{C}$, associated with humidity, and is considered as a major environmental barrier to outdoor physical activity.

One limitation in this study is that pedometers were distributed for free; thus, participants might be less committed to using it daily for $>6$ months. This might also be caused by the loss of pedometer or battery life, or even loss of interest in the program itself. On the other hand, participants might still be using the pedometer but not uploading the data 
frequently to the website. Another limitation is the fact that the sample under study is not representative of the general population. Moreover, the BMI results were not accurate due to the self-reported height and weight. Nevertheless, some strengths can be highlighted in this study, such as the accuracy of the step counts since it is uploaded on the website and not self-reported by the participants. Another strength is that the program is a community-based program and can reach a large section of the Qatari population.

\section{Conclusion}

Since physical activity recommendations require at least moderate-to-vigorous intensity, people should be more aware of the importance of aerobic steps and its implications, as well as raising awareness about the importance of physical activity and the WHO recommendations. Future research might need to consider barriers to physical activity as well as social, cultural, and environmental factors.

\section{Acknowledgments}

The authors would like to acknowledge Mohammed Farooq for his support in the data analyses consultation. We want to thank the "Step into Health" operational team for their contribution in the data acquisition process, implementation of the intervention and follow-up with the program members, and IT continuous maintenance and updates. We would also like to extend our appreciation to the Marketing team who assisted in the campaign advertisements. Finally, we would like to thank the members for believing in this project and participating in the program.

\section{Disclosure}

The authors report no conflicts of interest in this work.

\section{References}

1. World Health Organization [webpage on the Internet]. Physical Inactivity. Available from: http://www.who.int/dietphysicalactivity/pa/en/. Accessed April 30, 2015.

2. World Health Organization [webpage on the Internet]. Sedentary Lifestyle: A Global Public Health Problem. Geneva: World Health Organization; 2001. Available from: http://www.who.int/hpr/physactiv/sedentary. lifestyle.shtml/. Accessed May 21, 2015.

3. Boutayeb A, Boutayeb S. The burden of non-communicable diseases in developing countries. Int J Equity Health. 2005;4(1):2.

4. Amuna P, Zotor FB. Epidemiological and nutrition transition in developing countries: impact on human health and development. Proc Nutr Soc. 2008;67(1):82-90.

5. WHO. Global Status Report on Non-Communicable Diseases 2010. Geneva: World Health Organization; 2011. Available from: http://www. who.int/nmh/publications/ncd_report_full_en.pdf. Accessed April 30, 2015.

6. Rahim HFA, Sibai A, Khader Y, et al. Non-communicable diseases in the Arab world. Lancet. 2014;383(9914):356-367.
7. Haj Bakri A, Al-Thani A. Qatar STEPwise Report 2012: Chronic Disease Risk Factor Surveillance. Doha: Supreme Council of Health; 2013. Available from: http://www.who.int/chp/steps/Qatar_2012_ STEPwise_Report.pdf?ua=1. Accessed May 17, 2015.

8. World Health Organization. Global Recommendations on Physical Activity for Health. Geneva: WHO; 2010. Available from: http:// apps.who.int/iris/bitstream/10665/44399/1/9789241599979_eng.pdf. Accessed May 17, 2015.

9. Tudor-Locke C, Williams JE, Reis JP, Pluto D. Utility of pedometers for assessing physical activity: construct validity. Sports Med. 2004; 34(5):281-291.

10. Berk RA. Determination of optimal cutting scores in criterion-referenced measurement. J Exp Educ. 1976;45(2):4-9.

11. Haskell WL, I-Min L, Pate RR, et al. Physical activity and public health: updated recommendation for adults from the American College of Sports Medicine and the American Heart Association. Med Sci Sports Exerc. 2007;39(8):1423-1434.

12. Chief Medical Office, Department of Health, London. AT Least Five a Week: Evidence on the Impact of Physical Activity and its Relationship to Health-A Report from the Chief Medical Officer. London: Department of Health; 2004. Available from: http://www.bhfactive.org.uk/sites/ Exercise-Referral-Toolkit/downloads/resources/cmos-report-at-leastfive-a-week.pdf. Accessed May 30, 2015.

13. Qatar National Physical Activity [webpage on the Internet]. Qatar National Physical Activity Guidelines (NPAG-Q). 2014. Available from: http://www.namat.qa/NamatImages/Publications/75/QATAR\%20 PA\%20GUIDLINE\%20ENGLISH.PDF. Accessed May 21, 2015.

14. World Health Organization. Obesity: Preventing and Managing the Global Epidemic. Report of a WHO Consultation. Geneva: WHO; 2000. Available from: http://apps.who.int/iris/bitstream/10665/42330/1/ WHO_TRS_894.pdf?ua=1\&ua=1. Accessed June 2, 2015.

15. Tudor-Locke C, Bassett DR Jr. How many steps/day are enough? Preliminary pedometer indices for public health. Sports Med. 2004; 34(1):1-8.

16. Tudor-Locke C, Craig CL, Thyfault JP, Spence JC. A step-defined sedentary lifestyle index: $<5000$ steps/day. Appl Physiol Nutr Metab. 2013;38(2):100-114.

17. Omron Healthcare Inc [homepage on the Internet]. Omron Pedometer HJ-324U User Manual. 2012. Available from: www.omronhealthcare. com. Accessed May 21, 2015.

18. Ayabe M, Aoki J, Kumahara H, et al. Minute-by minute stepping rate of daily physical activity in normal and overweight/obese adults. Obes Res Clin Pract. 2011;5(2):e151-e156.

19. Pillay JD, van der Ploeg HP, Kolbe-Alexander TL, et al. The association between daily steps and health, and the mediating role of body composition: a pedometer-based, cross-sectional study in an employed South African population. BMC Public Health. 2015;15:174.

20. Marshall SJ, Levy SS, Tudor-Locke CE, et al. Translating physical activity recommendations into a pedometer-based step goal: 3000 steps in 30 minutes. Am J Prev Med. 2009;36(5):410-415.

21. Tudor-Locke C, Sisson SB, Collova T, Lee SM, Swan PD. Pedometerdetermined step count guidelines for classifying walking intensity in a young ostensibly healthy population. Can J Appl Physiol. 2005;30(6): 666-676.

22. Pillay JD, Kolbe-Alexander TL, Proper KI, van Mechelen W, Lambert EV. Steps that count-physical activity recommendations, brisk walking and steps per minute-how do they relate? J Phys Act Health. 2014;11(3):502-508.

23. Pillay JD, Kolbe-Alexander TL, van Mechelen W, Lambert EV. Steps that count-the association between the number and intensity of steps accumulated and fitness and health measures. JPhys Act Health. 2014; 11(1):10-17.

24. Owen N, Sparling PB, Healy GN, Dunstan DW, Matthews CE. Sedentary behavior: emerging evidence for a new health risk. Mayo Clin Proc. 2010;85(12):1138-1141.

25. Ng SW, Zaghloul S, Ali HI, Harrison G, Popkin BM. The prevalence and trends of overweight, obesity and nutrition-related non-communicable diseases in the Arabian Gulf States. Obes Rev. 2011;12(1):1-13. 
26. Musaiger A, Shahbeek N, Al-Mannai M. The role of social factors and weight status in ideal body-shape preferences as perceived by Arab women. J Biosoc Sci. 2004;36(6):699-707.

27. Berger G, Peerson A. Giving young Emirati women a voice: participatory action research on physical activity. Health Place. 2009;15(1): 117-124.

28. Cohen-Mansfield J, Marx MS, Guralnik JM. Motivators and barriers to exercise in an older community-dwelling population. JAPA. 2003;11(2): 242-253.

29. Buchowski MS, Acra S, Majchrzak KM, Sun M, Chen KY. Patterns of physical activity in free-living adults in the Southern United States. Eur J Clin Nutr. 2004;58(5):828-837.

30. Miller R, Brown W. Steps and sitting in a working population. Int $J$ Behav Med. 2004;11(4):219-224.

31. Tudor-Locke C, Ham SA, Macera CA, et al. Descriptive epidemiology of pedometer-determined physical activity. Med Sci Sports Exerc. 2004;36(9):1567-1573.

32. Zerubavel E. The Seven Day Circle: The History and the Meaning of the Week. Chicago: University of Chicago Press; 1989.
33. Monk RH, Buysse DJ, Rose LR, Hall JA, Kupfer DJ. The sleep of healthy people - a diary study. Chronobiol Int. 2000;17(1):49-60.

34. Racette S, Weiss E, Schechtman K, et al. Influence of weekend lifestyle on body weight. Obesity (Silver Spring). 2008;16(8):1826-1830.

35. de Castro JM. Weekly rhythms of spontaneous nutrient intake and meal pattern of humans. Physiol Behav. 1991;50(4):729-738.

36. Currie JL, Develin E. Stroll your way to well-being: a survey of the perceived benefits, barriers, community support, and stigma associated with pram walking groups designed for new mothers. Health Care Women Int. 2002;23(8):882-893.

37. Humpel N, Owen N, Iverson D, Leslie E, Bauman A. Perceived environment attributes, residential location, and walking for particular purposes. Am J Prev Med. 2004;26(2):119-125.

38. Salmon J, Owen N, Crawford D, Bauman A, Sallis JF. Physical activity and sedentary behavior: a population-based study of barriers, enjoyment, and preference. Health Psychol. 2003;22(2):178-188.
International Journal of Women's Health

\section{Publish your work in this journal}

The International Journal of Women's Health is an international, peerreviewed open-access journal publishing original research, reports, editorials, reviews and commentaries on all aspects of women's healthcare including gynecology, obstetrics, and breast cancer. The manuscript management system is completely online and includes

\section{Dovepress}

a very quick and fair peer-review system, which is all easy to use. Visit http://www.dovepress.com/testimonials.php to read real quotes from published authors.

\footnotetext{
Submit your manuscript here: http://www.dovepress.com/international-journal-of-womens-health-journal
} 